\title{
Commentary: Straight from the Horse's Mouth: Justification and Prevention Strategies Provided by Free-Riders on Global Virtual Teams
}

JiM JOHNSON

Corresponding author: jpjohnson@rollins.edu

Crummer Graduate School of Business

Rollins College, USA

There is strong evidence in the management literature that that diverse work teams produce better results than homogenous teams and, over the past several decades, businesses and other organizations have sought to implement policies to mandate or encourage diversity in a wide range of work teams, both temporary and permanent, from government bodies to board rooms to ad hoc project teams. There are many aspects to diversity: diversity in gender, age, work experiences, and cultural backgrounds are commonly cited, but diversity in political beliefs, sexual orientation, and personality characteristics can also assist in providing varied perspectives to discussions and decisionmaking. Yet diversity is a two-edged sword: as the team's size and diversity increases, it becomes more difficult to manage. The difficulty is exacerbated in teams that are geographically dispersed across country borders and time zones and are expected to coordinate their activities with the help of modern communication technology, from e-mail to group texting to video conference calls, to the use of collaborative software such as Microsoft Teams.

The use of global virtual teams (GVTs) has expanded exponentially, driven primarily by the availability of computer and telecommunications technologies that allow individuals to see, talk with, and exchange information with remotely-located peers at any time of the day or night. A recent survey of over 1600 respondents from 90 countries found that $89 \%$ of corporate employees serve on at least one global virtual team, of whom $62 \%$ work on teams with three or more cultures (Culture Wizard, 2018). GVTs offer many benefits to multinational organizations, including but not limited to access to lower-cost resources - such as highly trained IT specialists in Eastern Europe and India - and to local market knowledge. They also provide work teams with a diversity of perspectives across ages, genders, experience, and cultural backgrounds.

However, they also come at a cost - not only the investments in the technology and in training personnel in their use, but also the costs associated with the disadvantages of using GVTs. Among these are the downsides of diversity, where differences in age, gender, culture, and work experiences can create barriers to effective communication, barriers that are often not perceived by the team members. Miscommunication often occurs in exchanges between team members from low-context and high-context cultures. For example, a young female software engineer in South Korea might be reluctant to question or contradict an older, more senior colleague out of respect for her age and seniority; 
without an understanding of the deference given to seniority in the South Korean culture, team members might interpret her reluctance to speak up as her implied agreement with the more senior colleague.

Furthermore, the spatial distance between team members often makes it more difficult to resolve those issues that are perceived, since the widespread use of low-context communication technology such as e-mail might be insufficient to bridge the gap between low-context and high-context cultures. Also, as Meyer (2014) and others have shown, miscommunication among team members can occur not only between high-context and low-context cultures but is also dependent on the relative position of a national culture on the low-high context spectrum. Low-context Swiss Germans or Dutch members of a GVT might fail to correctly interpret a comment or suggestion from a relatively higher-context British speaker of English who couches her disagreement in an indirect way.

Taras and colleagues (2018) focus on a specific phenomenon that can occur in any work team, but is much more difficult to manage in a GVT - free-riding. Defined as "withholding [individual effort] on teams who share both responsibility and remuneration", they argue that free-riding is more likely to occur in larger and more diverse teams, especially those in which individual effort is not easily identifiable. They detect a number of causes of free-riding, offered by free-riders themselves, most of which can be reduced to a single concept: social distance. Neeley (2015) defines social distance as 'the degree of emotional connection among team members'. In a co-located work team, team members have the opportunity to meet regularly face-to-face as a team, or individually, to chat over the water-cooler, have lunch together, go for a drink after work, or even visit one another's home after work hours.

The intensity of regular interactions creates an emotional bond among members of the team which serves to mitigate the likelihood of free-riding. In the case of a geographically dispersed team, the opportunities for individual or group interactions diminish according to the spatial and temporal distance between the team members. The Culture Wizard (2018) survey of GVTs found that $76 \%$ of the respondents reported that their GVT included team members who did not participate. Thus, as Neeley (2015) states: "Mitigating social distance therefore becomes the primary management challenge for the global team leader." Note "the global team leader" - this person's role is essential to the success of the GVT, whether or not this person has a formal leadership role. Jang (2018) refers to "cultural brokerage" - the task of facilitating interactions between actors across cultural boundaries. The cultural broker is a team member, not necessarily a formal leader, who has relatively more multicultural experience than others in the team and can draw on his/her knowledge and experience to act as a bridge between the monocultural members of the team. The cultural broker may have direct knowledge of the cultures represented on the team - for example, an American who has lived and worked in Brazil for a number of years and is now in a GVT that consists of Americans and Brazilians- or may have knowledge and experience of other cultures not represented on the team, but can use this knowledge to bridge the cultural gap between team members - for example, that same American who has lived in Brazil could be a cultural broker between Americans and Mexicans, or between Mexicans and Indians, using his knowledge of another culture to invite team members to share information about their own culture.

Taras and colleagues (2018) note the need for training in the early stages of the GVT's project, a theme echoed in the Culture Wizard survey, where only $22 \%$ of respondents reported receiving any formal training on working in a GVT, and 24\% reported that their organization provided no guidelines or team charters. Communicating effectively across cultures, geographies, time-zones, and generations requires appropriate training since employees (or students) who are new to a GVT are likely to have little or no experience of doing so in a work environment and may be unaware of the barriers facing them.

Training and guidelines are essential to the success of a GVT, especially if the team relies primarily, or exclusively, on communication technology with a low level of contextual cues, such as e-mail. Team training should include 
time for team members to get used to the communications technology before the project starts: this allows the team members to deal with any technical glitches that might occur and to make alternative arrangements if necessary. This also has the benefit of allowing team members to indulge in small talk before the start of the project, to get to know one another's personality and cultural background, and to discuss preferences for how and when to communicate as a team. Although it would be preferable to do this via video conferencing, even an exchange via e-mail would serve to allow team members to learn about one another. This initial contact is also an opportunity for the members to discuss and agree on the desirability of a team contract.

Strong team leadership is another factor that can facilitate the success of a GVT. The leader should have some authority to direct the team since the assigning and coordination of tasks is an essential function of a leader. Ideally, the team leader is culturally savvy, too, and can take on the role of a cultural broker to make sure that everyone's voice is heard. Over $80 \%$ of the free-riders in the Taras et al. (2018) study reported that there was no leader of the team: without good leadership, a GVT is likely to flounder; add in poor quality and quantity of intra-team communication, and team members are more likely to get frustrated with one another and reduce their level of effort. The leader's job is to hold each team member accountable for his or her contribution to the project, but this cannot be achieved if the team leader has no perceived authority. This is less likely to occur in a workplace GVT than in a student GVT, since the assigned project leader is typically an employee who brings a high level of skills and experience to the team; nevertheless, the assigned leader should be aware of the different perceptions of leadership and communication across cultures; if not, appropriate training should be provided.

Finally, while it is good to have direct feedback "from the horse's mouth" on why GVT members become freeriders, we must be careful about projecting the dynamics of student teams onto the dynamics of real-life GVTs. The latter often contain team members who have significant experience of working in cross-cultural teams, both co-located and virtual; these teams typically have an appointed leader with the authority to assign tasks to individuals and to hold them to complete that task; potential free-riders in such a team risk not flunking a course, but demotion or the loss of a job, a sanction that is much more likely to deter free-riders. This is not to minimize the difficulties of managing a GVT, but taking steps to (1) appoint a knowledgeable team leader who is culturally savvy; (2) minimize the social distance among team members by giving team members the opportunities for learning about one another's culture through non-task discussions at the start of team meetings; (3) create a strong team spirit with an implied sense of social obligations, can all go a long way toward mitigating the incidence of free-riding.

\section{References}

Jang, Sujin, 2018. The Most Creative Teams Have a Specific Type of Cultural Diversity. Harvard Business Review, July. Accessed on July 23, 2018 at https://hbr.org/2018/07/the-most-creative-teams-have-a-specifictype-ot-cultural-diversity

Neeley, T., 2015. Global Teams That Work. Harvard Business Review, October: 74-81.

Taras, V., Tullar, W. L., Liu, Y. \& Pierce, J. R., 2018. Straight from the Horse' s Mouth: Justifications and Prevention Strategies Provided by Free Riders on Global Virtual Teams. In Doing Business in an Interconnected World: Cross-Cultural Issues in Management and Marketing. Special Issue of the Journal of Management and Training for Industries. G.J. Kivenzor (Ed.).

Wizard, C., 2018. 2018 Survey Report: Trends in Global Virtual Teams. Accessed on July 21, 2018 at https://www. $\mathrm{rw}-3$. com/resource-center 